International Journal of Current Advanced Research

ISSN: O: 2319-6475, ISSN: P: 2319 - 6505, Impact Factor: SJIF: 5.995

Available Online at www.journalijcar.org

Volume 6; Issue 3; March 2017; Page No. 2331-2333

DOI: http://dx.doi.org/10.24327/ijcar.2017.2333.0002

Research Article

\title{
NEUROBIOLOGICAL EFFECT OF PHYSICAL EXERCISE ON EUPHORIA
}

\author{
Rachel Paul ${ }^{*}$ and Jothi Priya ${ }^{2}$
}

1First year BDS, Saveetha Dental College \& Hospitals, Chennai-600 077

2Department of Physiology, Saveetha Dental College and Hospitals, Chennai-77

\begin{tabular}{l}
\hline A R T I C L E I N F O \\
\hline Article History: \\
Received $10^{\text {th }}$ December, 2016 \\
Received in revised form $7^{\text {th }}$ January, 2017 \\
Accepted $11^{\text {th }}$ February, 2017 \\
Published online $28^{\text {th }}$ March, 2017 \\
\hline
\end{tabular}

Kye Words:

Euphoria, physical exercise

\begin{abstract}
A B S T R A C T
Aim: To determine the influence of physical exercise on Euphoria

Objective: Euphoria is an affective state and form of pleasure in which a person experiences intense feelings of well-being, happiness and excitement. Certain drugs, many of which are addictive can cause euphoria.

Background: A survey will be taken at a gym to all those who have been doing exercise for a short term based on a few particular questions and conclusion will be made on the influence of physical exercise on euphoria.
\end{abstract}

Reason: To create awareness and make the society understand the value of aerobic exercise.

Copyright $₫ 2017$ Rachel Paul. This is an open access article distributed under the Creative Commons Attribution License, which permits unrestricted use, distribution, and reproduction in any medium, provided the original work is properly cited.

\section{INTRODUCTION}

Exercise is a physical activity that is planned, structured, and repetitive for the purpose of conditioning any part of the body. Exercise is used to improve health, maintain fitness and is important as a means of physical rehabilitation.

Exercise is useful in preventing or treating coronary heart diseases, osteoporosis, weakness, diabetes, obesity and mainly depression. The benefits of exercise not only improve physical health but also enhance emotional well-being. The potential use of aerobic exercise as an alternative or complementary treatment for depression has received considerable attention recently. [1]

Significant health benefits are obtained by including a moderate amount of physical exercise in the form of an exercise prescription. [2] Physical exercise plays a very important role in the change of the mental health of a person. Euphoria is a state in which a person experiences immense happiness, satisfaction and excitement. There are many drugs which can produce this state of happiness out of which many are addictive but aerobic exercise or even a walk around the place can induce a state of euphoria.

The word euphoria is derived from the Greek terms "eu" which means well and "pherō" which means "to bear".

*Corresponding author: Rachel Paul

First year BDS, Saveetha Dental College \& Hospitals, Chennai-600 077
There are different types of euphoria, that is, there are many factors for inducing a state of euphoria, they are exercise euphoria, music euphoria, drug induced etc.

Exercise and euphoria are related in many ways. Studies show show that exercise can treat a mild to moderate depression as effectively as antidepressant medication and mainly without side effects. In addition to relieving depression symptoms research so shows that maintaining an exercise schedule can prevent you from relapsing. Exercise is a powerful depression fighter for several reasons.[3]

\section{MATERIALS AND METHODS}

The sample has been selected randomly by the purposive methods containing 30 male and females. The age group was in between 18 and 30. Older people were not selected as they could have learnt through experience to relax. Experimental samples chosen were already going to the gym or for an aerobic exercise everyday. Out of which some of them go for an everyday workout and some of them prefer a once in week workout. The questionnaire enquiries about general questions -the change in food intake after starting gym, the amount of exercise done, whether preferred to work stress or not etc, which adds up to 10 questions. Interpretation of the answers is based on the multiple choice answers and essays of what their opinion are.

\section{RESULT AND DISCUSSION}

Exercise is also known as physical activity. In simple terms exercise is any movement that works your body at a greater intensity than your usual level of daily activity. Exercise 
raises your heart beat and works your muscles and is most commonly undertaken to achieve the aim of physical fitness and in some cases mental health too.[4] exercise aims to maintain or enhance our physical fitness and general health. There are two types of exercises- aerobic and anaerobic exercise. Out of which aerobic exercise are proved to show the following results.

- Reduces blood pressure

- Improves mental health

- Increases blood flow through muscles which makes feel relaxed and calm.

- Reduces the risks of heart diseases.[5]

\section{Effects of aerobic exercise}

There are many scientific studies that provide evidence of the beneficial effects of exercise on diseases prevention and overall health.[6]During aerobic exercises you move the large muscles in your legs, hips, and arms and your body responds quickly by breathing faster and deeper, your heartbeat increases accelerates increasing blood flow to your muscles and lungs. Capillaries widen to take more oxygen to your muscles and carry away carbon dioxide and lactic acid. Your body releases endorphins which are natural painkillers that create an enhanced sense of well being and which makes our mind relaxed and helps us concentrate on our daily work. Mind is affected as much as the body by aerobic exercise.[7]

\section{Acute exercise mechanisms}

There is evidence that physical exercise promotes changes in the human brain due to increases in metabolism, oxygenation and blood flow in the brain. Unfortunately, our knowledge of how the human brain is affected by physical exercise interventions is limited, and the available evidence is predominantly from animal studies.Studies with animals have shown that physical exercise modulates the major CNS neurotransmitters that are associated with an individual's state of alertness (norepinephrine), the pleasure and reward system (dopamine) and the level of anxiety (serotonin). Moreover, changes in the levels of these neurotransmitters may have different consequences depending on the type(s) of receptors and the cortical areas that are activated Other neurochemical factors that may be released during physical activities include opioids and endocannabinoids, which promote a sense of euphoria and well-being, anxiolytic effects, sedation and decreased sensitivity to pain in humans.[6]

\section{Effects of exercise on euphoria}

Two recent reviews focused on the effect of exercise on clinical depression. Mutrie summarised 10 key randomised controlled studies. Craft and Landers conducted a metaanalysis on all available studies where an exercise therapy for clinical depression had been used and produced a large mean effect size. Mutrie concluded

- Physical activity is associated with decreased risk of developing clinical depression.

- Experimental studies show that aerobic exercise is effective in treating depression.[8]

This is a strong evidence that exercise can help prevent and treat this common cause of manual illness and threat to mental well- being.

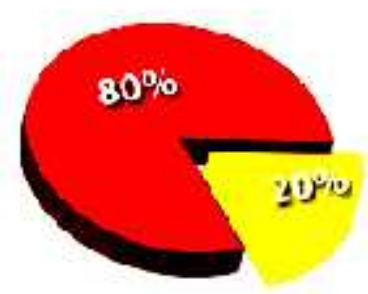

The main findings from this study demonstrates the strong association between physical activity and reduced odds of psychological distress. The mental health were benefits at a minimum physical activity of at least $30 \mathrm{~min} / \mathrm{week}$ of any type of activity. [9]

The effect of exercise as an adjunct to pharmacological treatment, on depressive symptoms has been studied. Both strength training and aerobic training have positive effects in the treatments of depression. [10]

From this study, based on the sample results, it can be concluded that $80 \%$ of the samples preferred to work under stress proving that exercise does make a difference in the mental health compared to pre workout session. And from this is can be concluded that physical exercise or aerobic exercise has a lot of influence in our body and helps us concentrate in our day to day work a lot better.

\section{CONCLUSION}

We can conclude that regular physical training can reduce the severity of several symptoms that are related to various mental disorders such as depression. There are many neurobiological hypotheses that may explain the wide variety of observed responses to exercise. Acute exercise appears to improve mood by activating specific cortical areas and by inducing the release of neurotransmitters and trophic factors that contribute to adherence to a program of regular physical activity. Chronic physical exercise appears to induce both neurogenesis and angiogenesis, which are important for improving behavioural and cognitive function and for improving the health of patients with mental disorders. Moreover, as the studies of athletes that were discussed in this article have shown, physical exercise can modulate mental health in both constructive and destructive. [10]

\section{Reference}

1. Effects of exercise training on older patients with major depression-James A. Blumenthal, Ph.D., Michael A. Babyak, Ph.D., Kathleen A. Moore, Ph.D.

2. Exercise-dictionary, thesaurus, legal, financial, encyclopaedia, Wikipedia

3. The mental health benefits of exercise- help guide.org

4. What is exercise-by WLR's personal trainer, Nicola Granville PTI REP level 3

5. Exercise: health benefits, types and how it works Christian nordqvist.

6. Neuroscience of exercise: from neurobiology mechanisms to mental health- Matta Mello Portugal, Cevada, SobralMonterio- junior R, TeixeriaGuimaraes T. da Cruz Rubin's E, Lattari E, Blois C.Camas Deslandes.

7. Long term effect of aerobic exercise by Betty Holt 
8. The influence of physical activity on mental well being by Dr.Kenneth $\mathrm{R}$ Fox, department of exercise and health science, university of Bristol, UK

9. The effect of selected relaxation training with physical activity on mental well being- masoumehAliasghary, Kharazmi university
10. Neuroscience of exercise: from neurobiology mechanisms to mental health-Matta Mello Portugal, Cevada, SobralMonterio- junior R, TeixeriaGuimaraes T. da Cruz Rubin's E, Lattari E, Blois C. Camas Deslandes.

\section{Please cite this article in press as:}

Rachel Paul and Jothi Priya (2017), Neurobiological Effect of Physical Exercise on Euphoria, International Journal of

Current Advanced Research, 6(3), pp. 2331-2333. http://dx.doi.org/10.24327/ijcar.2017.2333.0002

$* * * * * * *$ 